\title{
DNA Profiling, Pedigree Lineage Analysis and Monitoring in the Australian Breeding Program of Radiata Pine
}

\author{
By J. C. Bell ${ }^{1}$, M. Powell ${ }^{2}$, M. E. Dever ${ }^{1}$ and G. F. Moran ${ }^{1 *}$
}

(Received 11 ${ }^{\text {th }}$ August 2004)

\begin{abstract}
Ten microsatellite loci were used to DNA profile 215 first and second generation breeding clones in the Australian radiata pine breeding program. The clones were essentially unique from one another and these DNA profiles were used to examine the sexual and asexual phases in the breeding program. Only $2.6 \%$ of ramets from 25 breeding clones were incorrect whereas $8.4 \%$ of progeny from 10 families were genetically incorrect. The lineages of second generation clones were checked for DNA profiles that were available for putative parents. Some parents appear to be incorrect on the basis of the DNA profiles and further sampling will be required to confirm these results across the breeding program. Microsatellite markers can now enable most questions to be resolved in breeding programs and also will allow novel breeding strategies to be used in the future.
\end{abstract}

Key words: DNA fingerprinting, microsatellite loci, probability of identity, paternity.

\section{Introduction}

In tree breeding programs with long generation times, the quality of breeding programs relates to maximising genetic gain while minimising inbreeding. With the advent of highly variable molecular markers such as microsatellites the monitoring of quality control in such breeding programs can be routine. A program of quality control can be established to check for error levels at various points in the breeding program. Some critical points of decision are, clonal identity of breeding lines, correct parentage of fullsib crosses and lineage of breeding lines across generations. In order to achieve these outcomes, a baseline needs to be established consisting of DNA profiles of multilocus microsatellite genotypes of appropriate selection lines from the breeding program.

With the high level of variability of microsatellites there is a low probability of two individuals having the same genotype by chance, and this probability of identity (PI) was formulated by PAETKAU and STROBECK (1994). In breeding programs there is likely to be some degree of relatedness among lines especially over generations and a relevant parameter is the probability of identity among fullsib progeny (EvETT and WEIR, 1998). With the degree of relatedness unknown, these two estimates give upper and lower limits on PI (TABERLET and LUIKART, 1999). These estimators are particularly relevant when the primary concern is individual identification of diploid genotypes such as in clonal identification and unique identification of breeding lines. However, monitoring of a breeding program often requires parentage analysis where the main issue is the assignment of the haploid contribution to potential parents.

The haploid contribution to offspring in plants or tree breeding programs is usually an issue on the paternal side. Often the main concern is the paternity itself rather than gene flow

\footnotetext{
${ }^{1}$ CSIRO Forestry and Forest Products. PO Box E4008 Kingston ACT 2604.

2 Southern Tree Breeding Association, PO Box 1811 Mount Gambier SA 5290 .

* Corresponding author: gavin.moran@csiro.au
}

or reproductive success. For advanced tree breeding programs the experimental situation is often closed in the sense that the paternal contribution is from a known set of potential fathers. With these data types two common approaches would be essentially an exclusion process such as used in NEWPAT (WoRTHINGTON WILMER et al., 1999) or a likelihood approach (MARSHALL et al., 1998). The more general situation is when not all parents are known and various fractional assignment methods have been used to assign paternity (ROEDER et al., 1989, NiELSEN et al., 2001). JoNES and ARDEN (2003) present a review of these methods. An alternative approach would be to use the neighbourhood model in which gene flow and factors affecting male reproductive success are estimated simultaneously (ADAMS and BIRKES, 1991, BURCZYK et al., 2002).

Breeding programs of commercially important forest tree species are only in their infancy compared to most crop species. The limiting factors are the long breeding cycle and the timeframe to evaluation of commercial traits such as growth and wood properties. In radiata pine, the major softwood plantation species of the southern hemisphere, two generations of selection have been completed in the Australian breeding program. Selections are clonally propagated and the majority of the deployment material is seed from clonal seed orchards. First generation selections were made in plantations, which originated from Californian native populations (MORAN and BELL, 1987). The second generation selections were either from fullsib or open-pollinated families in field trials.

The aims of this study were to test the ability of SSR markers for DNA profiling of Pinus radiata and to monitor the genetic quality of the Australian Pinus radiata breeding program by using pedigree analysis. A previously determined set of ten microsatellites (DEveY et al., 2002) were used to establish DNA profiles of first and second generation breeding clones, which were then used to check sexual and asexual phases of the breeding program and to analyse lineages of pedigrees within the breeding program.

\section{Materials and Methods \\ Sampling of breeding material}

Breeding clones were selected on the basis of their inclusion in the current Southern Tree Breeding Association (STBA) breeding program and/or having high multi-purpose values from the STBA breeding value calculations. Needle samples were collected from 120 clones from the STBA first generation breeding selections and from 95 clones from the STBA second generation breeding selections. Samples were collected from ramets in clone banks or breeding arboreta in South Australia, Tasmania, and two regions in Victoria.

Error levels in clonal reproduction were assessed by sampling needles from ramets of each of 25 clones at up to four different regional sites. The aim was to sample five ramets of each clone from each of four sites. To assess error levels in controlled fullsib crosses across families and sites, 10 families in four field sites and five progeny per family per site were sampled. 
Selection of second generation breeding clones for parentage analysis was based on those clones that originated from fullsib crosses and first generation parents with known DNA profiles.

\section{DNA extraction and microsatellite genotyping}

DNA was extracted from each needle sample, quantified, diluted to $20 \mathrm{ng} / \mathrm{ul}$ and stored at $4{ }^{\circ} \mathrm{C}$ using standard procedures (Devey et al., 1996). The microsatellites assayed consisted of the ten recently reported for the DNA fingerprinting of Pinus radiata (DEvey et al., 2002) except that two microsatellites, Pr070 and Pr114, were substituted for Pr001 and Pr9.3. Each DNA sample was amplified in four multiplex reactions (mix 1, Pr233 + Pr118; mix 2, Pr111 + Pr254; mix 3, Pr284 + Pr011 + Pr265; mix 4, Pr070 + Pr4.6 + Pr114) with PCR amplification conditions of; $94^{\circ} \mathrm{C}$ for 2 mins, $30 \times\left(94^{\circ} \mathrm{C}\right.$ for 15 secs, $55^{\circ} \mathrm{C}$ for 30 secs, $72^{\circ} \mathrm{C}$ for 30 secs), $72^{\circ} \mathrm{C}$ for $10 \mathrm{mins}$, hold at $4^{\circ} \mathrm{C}$, and with a $\mathrm{Mg}^{2+}$ concentration of $2.5 \mathrm{mM}$. The amplified products were then combined into two fragment analysis runs (mix 1 and mix 2 together, and mix 3 and mix 4 together) on a Beckman-Coulter CEQ8000 machine. Up to three microsatellite marker loci could be PCR amplified together providing the oligonucleotide primers did not have complementary sequence regions, and by using primer concentrations of $0.2 \mathrm{uM}$ each. Any number of microsatellite loci can be assayed in the same fragment analysis run providing they are separated from each other by either size or fluorescent dye colour. The primer sequences are as given in DEVEY et al. (2002) and are also available at http://www.ffp.csiro.au/tigr/molecular/pinessr.html. The CEQ8000 software was then used to produce tables of allele sizes for each microsatellite locus for each DNA sample.

\section{Genetic analyses}

Measures of allelic diversity (including $\mathrm{A}, \mathrm{H}_{\mathrm{e}}$ and $\mathrm{F}$ ) were calculated with the FSTAT program (GOUDET, 1995). The probability of identity (PI, the probability that two genotypes are the same by chance rather than being the same clone; $\mathrm{PI}$, the probability that two genotypes from a sibling array are the same by chance rather than being the same clone) was calculated using the formulae in TABERLET and LUIKART (1999). The average exclusion probability for parents was estimated from the genotypes of the offspring and other parent, using the program CERVUS (MARSHALL et al., 1998) and the formulae of JAMIESON (1994). Pic was calculated by the CERVUS program.
Parentage analysis of fullsib crosses was carried out in three ways. The first method was compatibility of progeny genotypes with putative mother and paternal genotypes.

The second was essentially an exclusion method based on the NEWPAT program. We allowed 1 mismatch (WoRTHINGTON WiLMER et al., 1999, AMos, http://www.zoo.cam.ac.uk/zoostaff/ amos/newpat.htm).

The third method was based on a likelihood approach in which critical log-likelihood scores are generated to assign paternity at a given level of statistical confidence (CERVUS version 2.0, MaRShall et al., 1998, Slate et al., 2000, http://helios.bto.ed.ac.uk/evolgen).

\section{Results \\ Levels of genetic diversity}

A total of 215 breeding clones from the first and second generation breeding programs were assayed for genotypes at ten microsatellite loci. At these loci there was a range in number of alleles from 6 to 21 with an average of 11.4 alleles per locus (Table 2). Allelic frequencies are given in Table 1 and show that (61) $53.5 \%$ of alleles are rare $(<5 \%)$ while $11(9.6 \%)$ occur at a frequency of greater than 0.25 . Clearly the distribution of alleles at some loci results in greater genetic discrimination than at others. For instance Pr011 has 14 alleles but none at a frequency greater than 0.25 , whereas Pr114 has only 9 alleles but just three contribute to greater than $90 \%$ of total frequency. This is reflected in the probability of identity estimates for the individual loci (Table 2) in which Pr011 has the lowest PI values and Pr114 the highest. It appears that a large number of alleles, plus an even distribution of allele frequencies, are requirements for obtaining a low probability that two clones will be genetically the same by chance. The PI values also show that when distinguishing between clones that are sibs, more variation at loci (and more loci) will be needed than for clones that are not related. The genetic diversity among the breeding clones was high (Table 2) and was to be expected given the prior selection process of microsatellite loci (DEVEY et al., 2002). The expected heterozygosity per locus ranged from 0.652 to 0.882 with a mean of 0.783 and were very similar to the Pic values. The $\mathrm{F}$ values were low indicating a very low occurrence of nulls, reflecting the previous selection against microsatellite loci with significant occurrence of nulls.

Table 1. - Allele sizes and frequencies at ten microsatellite marker loci in 215 Pinus radiata trees.

\begin{tabular}{|c|c|c|c|c|c|c|c|c|c|c|c|c|c|c|c|c|c|c|c|}
\hline \multicolumn{2}{|c|}{ Pr111 } & \multicolumn{2}{|c|}{ Pr118 } & \multicolumn{2}{|c|}{ Pr233 } & \multicolumn{2}{|c|}{ Pr254 } & \multicolumn{2}{|c|}{ Pr114 } & \multicolumn{2}{|c|}{ Pr265 } & \multicolumn{2}{|c|}{ Pr284 } & \multicolumn{2}{|c|}{ Pro11 } & \multicolumn{2}{|c|}{ Pr070 } & \multicolumn{2}{|c|}{ Pr4.6 } \\
\hline 104 & 0.003 & 219 & 0.148 & 118 & 0.036 & 152 & 0.002 & 111 & 0.015 & 269 & 0.019 & 104 & 0.028 & 156 & 0.044 & 147 & 0.197 & 187 & 0.005 \\
\hline 106 & & 221 & 0.025 & 120 & 0.022 & 154 & & 113 & & 271 & 0.107 & 106 & 0.442 & 158 & 0.016 & 149 & & 189 & \\
\hline 108 & 0.089 & 223 & 0.027 & 122 & 0.029 & 156 & & 115 & & 273 & 0.007 & 108 & 0.151 & 160 & & 151 & & 191 & \\
\hline 110 & & 225 & 0.102 & 124 & 0.263 & 158 & 0.024 & 117 & 0.012 & 275 & 0.039 & 110 & 0.026 & 162 & 0.037 & 153 & & 193 & \\
\hline 112 & 0.102 & 227 & 0.442 & 126 & 0.176 & 160 & 0.293 & 119 & & 277 & 0.197 & 112 & & 164 & 0.131 & 155 & 0.085 & 195 & \\
\hline 114 & 0.107 & 229 & 0.190 & 128 & 0.099 & 162 & 0.198 & 121 & 0.197 & 279 & 0.260 & 114 & & 166 & 0.056 & 157 & & 197 & \\
\hline 116 & 0.051 & 231 & 0.036 & 130 & 0.034 & 164 & 0.263 & 123 & 0.507 & 281 & 0.087 & 116 & 0.002 & 168 & 0.166 & 159 & & 199 & 0.010 \\
\hline 118 & 0.459 & 233 & 0.011 & 132 & 0.056 & 166 & 0.061 & 125 & 0.231 & 283 & 0.027 & 118 & 0.260 & 170 & 0.159 & 161 & 0.070 & 201 & 0.125 \\
\hline 120 & 0.188 & 235 & 0.019 & 134 & 0.094 & 168 & 0.027 & 127 & 0.024 & 285 & 0.058 & 120 & 0.091 & 172 & 0.168 & 163 & 0.357 & 203 & 0.268 \\
\hline 122 & & & & 136 & 0.027 & 170 & 0.120 & 129 & & 287 & 0.010 & & & 174 & 0.028 & 165 & 0.250 & 205 & 0.068 \\
\hline 124 & 0.003 & & & 138 & 0.029 & 172 & 0.012 & 131 & & 289 & 0.005 & & & 176 & 0.040 & 167 & 0.041 & 207 & \\
\hline & & & & 140 & 0.007 & & & 133 & 0.002 & 291 & & & & 178 & 0.093 & & & 209 & 0.010 \\
\hline & & & & 142 & 0.041 & & & 135 & & 293 & 0.027 & & & 180 & 0.005 & & & 211 & 0.108 \\
\hline & & & & 144 & 0.010 & & & 137 & 0.010 & 295 & 0.117 & & & 182 & 0.051 & & & 213 & 0.010 \\
\hline & & & & 146 & & & & null & 0.002 & 297 & 0.012 & & & 184 & 0.005 & & & 215 & 0.013 \\
\hline & & & & 148 & 0.051 & & & & & 299 & 0.024 & & & & & & & 217 & 0.135 \\
\hline & & & & 150 & 0.005 & & & & & 301 & & & & & & & & 219 & 0.055 \\
\hline & & & & 152 & 0.007 & & & & & 303 & & & & & & & & 221 & 0.028 \\
\hline & & & & 154 & 0.002 & & & & & 305 & & & & & & & & 223 & 0.020 \\
\hline & & & & 156 & 0.005 & & & & & 307 & 0.005 & & & & & & & 225 & 0.045 \\
\hline & & & & 160 & 0.005 & & & & & & & & & & & & & 227 & 0.103 \\
\hline & & & & null & 0.002 & & & & & & & & & & & & & & \\
\hline
\end{tabular}


Table 2. - Genetic diversity measures for $2151^{\text {st }}$ and $2^{\text {nd }}$ generation breeding clones of radiata pine.

\begin{tabular}{|c|c|c|c|c|c|c|c|c|}
\hline Locus & $\mathbf{A}$ & $\mathbf{H}_{\mathbf{0}}$ & $\mathbf{H}_{\mathrm{e}}$ & $\mathbf{F}$ & Pic & PI & $\mathbf{P I}_{\mathbf{s}}$ & PE \\
\hline $\operatorname{Pr} 111$ & 8 & 0.68 & 0.72 & 0.063 & 0.69 & 0.1090 & 0.1915 & 0.514 \\
\hline $\operatorname{Pr} 118$ & 9 & 0.63 & 0.74 & 0.140 & 0.70 & 0.1025 & 0.1841 & 0.525 \\
\hline $\operatorname{Pr} 233$ & 21 & 0.78 & 0.87 & 0.118 & 0.86 & 0.0289 & 0.0982 & 0.744 \\
\hline $\operatorname{Pr} 254$ & 9 & 0.80 & 0.79 & -0.017 & 0.75 & 0.0773 & 0.1511 & 0.586 \\
\hline $\operatorname{Pr} 114$ & 9 & 0.65 & 0.65 & -0.009 & 0.60 & 0.1748 & 0.2438 & 0.399 \\
\hline $\operatorname{Pr} 265$ & 16 & 0.79 & 0.85 & 0.073 & 0.84 & 0.0364 & 0.1073 & 0.713 \\
\hline $\operatorname{Pr} 284$ & 7 & 0.67 & 0.71 & 0.036 & 0.66 & 0.1314 & 0.2057 & 0.468 \\
\hline Pr011 & 14 & 0.90 & 0.88 & -0.024 & 0.87 & 0.0256 & 0.0908 & 0.761 \\
\hline Pr070 & 6 & 0.73 & 0.76 & 0.032 & 0.72 & 0.0958 & 0.1701 & 0.539 \\
\hline $\operatorname{Pr} 4.6$ & 15 & 0.81 & 0.86 & 0.050 & 0.85 & 0.0325 & 0.1025 & 0.729 \\
\hline Overall & 11.4 & 0.74 & 0.78 & 0.046 & 0.75 & $1.66 \times 10^{-12}$ & $4.46 \times 10^{-9}$ & 0.999 \\
\hline
\end{tabular}

$\mathrm{A}=$ no of alleles per locus, $\mathrm{H}_{\mathrm{o}}=$ observed heterozygosity, $\mathrm{H}_{\mathrm{e}}=$ expected heterozygosity, $\mathrm{F}=$ fixation index, Pic $=$ Polymorphic information content, $\mathrm{PI}=$ probability of identity for a random sample, $\mathrm{PI}_{\mathrm{s}}=$ probability of identity for a sibling array, $\mathrm{PE}=$ probability of exclusion of incorrect putative second parents given that one parent is known. Overall values for PI, PIs and PE are cumulative using all loci.

\section{Genetic uniqueness of breeding clones}

In Figure 1 the cumulative probabilities across loci are given for the probability that two breeding clones are the same by chance. Loci were added in order of increasing PI values. The plots suggest that at least four loci will be needed to uniquely identify clones at random and perhaps six loci if there is the potential that the clones are sibs.

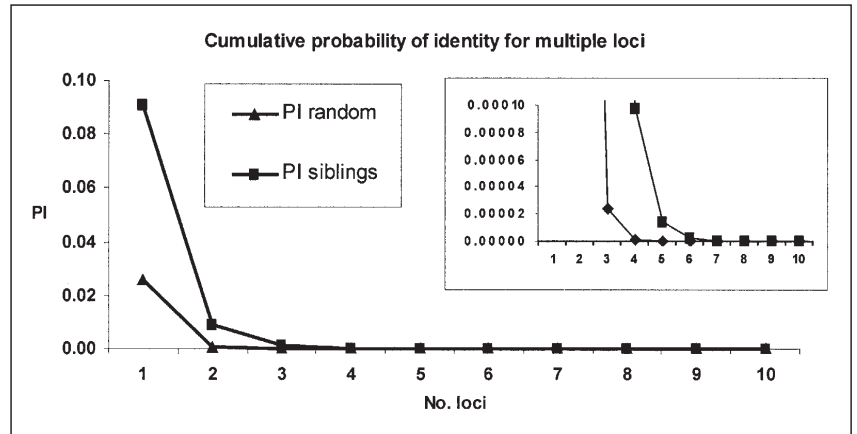

Figure 1. - Relationship between number of loci and probability of finding two identical genotypes when (1) breeding clones are chosen at random and (2) breeding clones are sibs. The insert shows part of the same graph at a different scale.

In the radiata breeding program multilocus genotypes were determined for 215 first and second generation clones. All breeding clones were essentially unique with four exceptions. These four clones were only assayed from one ramet and given the very low probabilities that DNA profiles of any two clones will be the same; it suggests sampling errors in the process. Without further testing of the same and other ramets of these breeding clones the source of the problem cannot be resolved.

\section{Fidelity of clones and families}

A total of 386 ramets from 25 selected clones were assayed to determine the error levels in the asexual reproduction component of the breeding program (Table 3). A consensus multilocus genotype was determined for each clone because of the availability of multiple samples. In two clones this allowed the identification of null alleles, one at locus Pr233 and one at locus Pr114 (Table 1).

Overall, 10 (2.6\%) of the 386 ramets assayed had genotypes inconsistent with the expected consensus multilocus genotype. Not surprisingly, given the high marker variability, incorrect
Table 3. - Determination of incorrect individuals within (a) breeding clones and (b) families of the radiata pine breeding program.

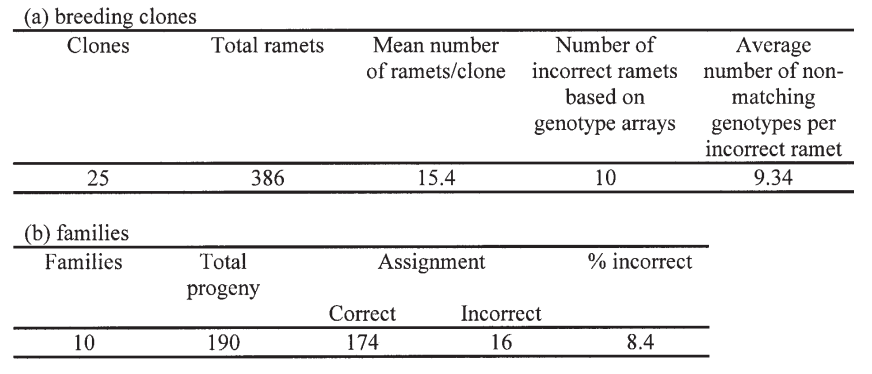

ramets had marker genotypes not consistent with consensus genotypes at most loci. The incorrect ramets were not restricted to a few breeding clones with the incorrect ramets coming from eight breeding clones. The range in error levels across regional sites was $1.1 \%-4.6 \%$ and there does not appear to be significant site error effects. Seven of the ten incorrect ramets have multilocus genotypes consistent with other breeding clones in the database. Without further duplicate analyses it cannot be determined whether errors in samples were in labelling, in the field or the laboratory.

In Table 3 the overall assessment of progeny from ten fullsib families showed that 16 out of 190 progeny had genotypes not consistent with segregation of the expected parental genotypes at all loci. Where possible, each family was represented by five progeny from each of four field trial sites. There was little evidence of a pattern in the errors, which occurred in five families, and the range in errors across all regional sites was $4.1 \%-15.6 \%$. A notable exception was one family at one site where all five progeny were incorrect. These five progeny did not carry the expected maternal or paternal alleles. Overall of the 16 incorrect progeny, 10 carry maternal alleles at every locus and could be pollination errors on the correct mother trees. The 16 were also found to be incorrect on the basis of likelihood (CERVUS) and exclusion (NEWPAT) analyses.

The probability of exclusion (PE) was calculated for the genotype arrays for the 215 first and second generation selections. Figure 2 shows cumulative PE as loci are added in decreasing $\mathrm{PE}$ values when the genotype of one parent is known. The estimated $\mathrm{PE}$ value for 10 loci was 0.9998 and it is clear that the six most discriminating loci should be sufficient to determine the second parent unequivocally. Of the 190 progeny in the above fullsib crosses, complete genotype data were available at six or more loci for 137 progeny. These 137 progeny from 10 


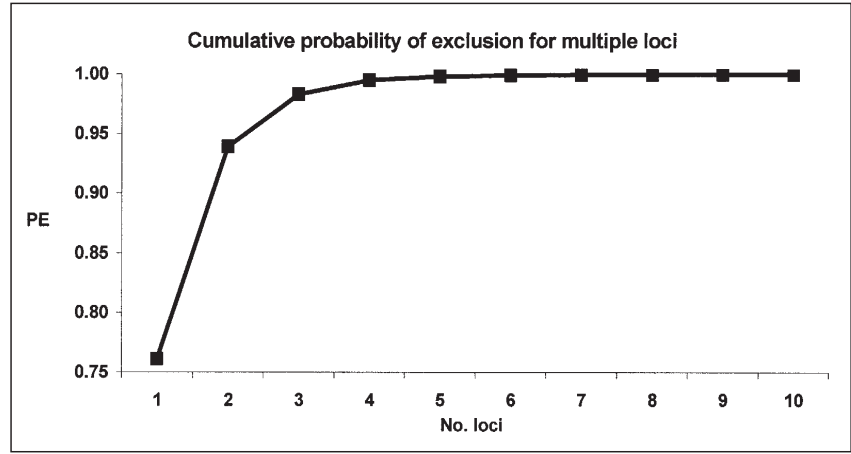

Figure 2. - Cumulative average probability of exclusion of incorrect putative second parents given that one parent is known.

families were assessed for paternal assignment by three methods. Firstly, the progeny multilocus genotypes were assessed as to whether they were compatible with the putative maternal and paternal multilocus genotypes. All progeny had genotypes consistent with parental genotype arrays. When all breeding clones with DNA profiles were used as a source of potential fathers, a likelihood approach (CERVUS see MARSHALL et al., 1998) assigned $12(8.7 \%)$ progeny to another paternal parent rather than the correct putative parent. For half of these assignments a related parent (either sibling or grandparent) was selected. In contrast with NEWPAT, primarily an exclusion method, only $5.8 \%$ of assignments were different to the expected paternal parents but again $50 \%$ of these were relatives. These results suggest that paternal clonal contribution of seed could be determined with reasonable accuracy when mothers are known and the potential fathers are unknown. A limitation may be the degree of relatedness between putative fathers.

\section{Lineages in breeding programs}

Of the 95 second generation selections that were DNA profiled, 32 were from controlled cross progeny for which both putative parents were DNA profiled. When the parentages of these second generation selections were tested against the database, four selections were found to be incorrect (Table 4). It appeared that three had incorrect mothers compared to the known lineage whereas the other had an incorrect father. Only ramets of putative parents were tested so it is unclear where the source of error is. For instance, the ortets of the four second generation breeding selections could still be correct and errors made subsequently either in the cloning step or seed generation in the clonal seed orchard. Forty-three of the second generation breeding clones were selections in open-pollinated trials where the mother is known and has been DNA profiled. We can test whether the multilocus genotypes of the mothers are consistent with being the putative mothers of these 43 breeding clones. The putative maternal parent was judged incorrect on the criterion that at $30 \%$ or more of the loci, the genotypes of the mothers were incorrect. This criterion was used to avoid false exclusions of correct parents resulting from possible genotyping errors, null alleles and mutations (JONES and ARDREN, 2003). Five of the 43 second generation breeding clones (11.6\%) had incorrect mothers at the $5 \%$ level of significance.

\section{Discussion}

With microsatellite loci the estimated level of genetic diversity in the base breeding population of radiata pine is more than eight times that from isozyme loci (MORAN and BELL, 1987). This result is despite the fact that radiata pine has been traditionally considered to have low levels of diversity (MORAN et al., 1988) compared to many other conifers such as Douglas-fir
Table 4. - Lineage analysis to test the accuracy of $2^{\text {nd }}$ generation pedigrees in the Australian Pinus radiata breeding program.

\begin{tabular}{|c|c|c|c|c|c|}
\hline \multirow[t]{2}{*}{ Type of lineage } & \multirow{2}{*}{$\begin{array}{c}\text { Number of } \\
\text { breeding clones }\end{array}$} & \multirow{2}{*}{$\begin{array}{l}\text { Correct } \\
\text { genotype }\end{array}$} & \multicolumn{2}{|c|}{ Incorrect genotype } & \multirow{2}{*}{$\begin{array}{c}\% \\
\text { incorrect }\end{array}$} \\
\hline & & & Maternal & Paternal & \\
\hline Control Pollinated & 32 & 28 & 3 & 1 & 14.3 \\
\hline Open Pollinated & 43 & 38 & 5 & - & 11.6 \\
\hline
\end{tabular}

(CONKLE, 1992). Such high levels of genetic diversity enable unique genetic separation of breeding material without expending resources on assays of large numbers of loci. Figure 1 shows the probability of identity for increasing numbers of marker loci. Clearly ten loci are more than sufficient to uniquely identify breeding clones in the Australian breeding program of radiata pine, even for second generation clones where there is a degree of commonality in parents between a number of clones. However, the degree of relatedness between first generation clone selections is unknown since they were made in plantations of unclear seed source.

There is a trade-off in terms of strategy to minimise the effort and resources required to maximise genetic discrimination. Cost-effective procedures are needed to enable routine monitoring in operational tree breeding programs. Some important factors influencing individual identification of breeding clones are number of loci and number and frequency of alleles at these loci. An upper bound on number of alleles would be desirable to avoid difficulties in scoring and allele misclassification and also a preference for loci where allele frequencies are roughly equal. Six loci with 10 alleles at equal frequency and that could be multiplexed in one PCR would be an ideal goal. Some of these were goals for loci selection in DNA fingerprinting of radiata pine (DEVEY et al., 2002).

In the breeding cycle errors will have a more detrimental impact on long term genetic gain at some points compared to others. In essence, the aim is to halt accumulation of errors and not to compound them over breeding cycles. A key point is when material goes though to the next generation in the breeding program. The first checkpoint would be the correctness of the ramets of clones in breeding arboreta on which crosses are going to be made for progeny trials from which new selections will eventually be made. On average about $10 \%$ of ramets were found to have the incorrect genotype in species such as Douglas-fir, Scots pine and loblolly pine (ADAMS, 1983; HARJU and MuONA, 1989; WhEeler and JECH, 1992). The average figure in this study of $2.6 \%$ is therefore low, especially when it is considered that overall PI values with the microsatellites are so low that all errors should be detected unequivocally, unlike perhaps with isozyme markers used in earlier studies. Nevertheless, monitoring of ramets of important breeding clones would seem an obvious first step.

The second point in the breeding cycle would be the fullsib progeny already under test in trials and from which selections are to be made. In other breeding programs errors have been found to be substantial (ADAMS, 1983). Given an overall error level of $8.4 \%$ in radiata pine families and that these errors are distributed across families and regional sites, as a minimum, selections of radiata pine made in progeny trials should be genotyped for testing. This study showed that a small suite of microsatellite markers is sufficiently powerful to enable monitoring of these key points in the breeding cycle.

With isozymes it was possible to narrow the origin of radiata pine in Australia to Monterey and Ano Nuevo populations in California (MORAN and BeLL, 1987; Moran et al., 1988). However finer resolution of origins within subpopulations or proportions from populations may now be possible using as a baseline the gene frequencies established in the breeding material 
in this study. The distribution of alleles at loci assayed may be sufficient to pinpoint likely subpopulations of Monterey and Ano Nuevo that have contributed genetic resources to the breeding program, but additional loci would be required for accurate comparisons of genetic diversity levels between the breeding program and the native populations.

An important component of a breeding program is the pedigrees or lineages, which connect up the different breeding cycles. The DNA profiles of the breeding clones allow certainty of parentage identification and lineages can be checked with confidence.

The very high PE values for the breeding clone populations allowed assignment of parents to second generation selections based on DNA profiles. On average about $13 \%$ of clones had genotypes inconsistent with at least one expected parent. A checking procedure across ramets of these clones should be put in place. The process could be extended to all second generation selections if DNA profiles of all the relevant putative first generation parents were determined. Extension of this research could focus on potentially closed systems such as clonal seed orchards from which were sourced a substantial number of first generation selections via open-pollinated progeny trials. A potential limitation may be the generally high pollen contamination in conifer seed orchards (ADAMS and BURCZYK, 2000), although this has not been quantified in radiata pine orchards. In theory it could enable the determination of paternal parents of such selections, hence elucidation of lineages in retard and more precise estimation of relatedness in breeding programs over time.

\section{Acknowledgements}

We thank REDDY THumma for comments on the manuscript.

\section{References}

ADAMs, W. T. (1983): Application of isozymes in tree breeding. In: Isozymes in Plant Genetics and Breeding. Eds: TANSKLEY, S. D. and Orton, T. J. Elsevier Science Publishers, Amsterdam, Part A. pp. 381-400.

ADAMs, W. T. and BiRKES, D. S. (1991): Estimating mating patterns in forest tree populations. In: Biochemical Markers in the Population Genetics of Forest Trees. Eds: Fineschi, S., Malvolti, M. E., Cannata, F., Hattemer, H. H., pp. 157-172. SPB Academic Publishing, The Hague, The Netherlands.

Adams, W. T. and BurczyK, J. (2002): Magnitude and implications of gene flow in gene conservation reserves. In: Forest Conservation Genetics: Principles and Practice. Eds: Young, A., Boshier, D., Boyle, T., pp. 215-224. CSIRO Publishing, Collingwood, Australia.

BurczyK, J., Adams, W. T., Moran, G. F. and Griffin, A. R. (2002): Complex patterns of mating revealed in a Eucalyptus regnans seed orchard using allozyme markers and the neighborhood model. Molecular Ecology 11: 2379-2391.

CONKLE, M. T. (1992): Genetic diversity-seeing the forest through the trees. New Forests 6: 5-22.
Devey, M. E., Bell, J. C., Smith, D. N., Neale, D. B. and Moran, G. F. (1996): A genetic linkage map for Pinus radiata based on RFLP, RAPD, and microsatellite markers. Theoretical and Applied Genetics 92: 673-679.

Devey, M. E., Bell, J. C., Uren, T. L. and Moran, G. F. (2002): A set of microsatellite markers for fingerprinting and breeding applications in Pinus radiata. Genome 45: 984-989.

EvETT, I. W. and WEIR, B. S. (1998): Interpreting DNA evidence: Statistical Genetics for Forensic Scientists. Sinauer, Sunderland.

GOUDET, J. (1995): FSTAT(vers. 1.2): a computer program to calculate F-statistics. Journal of Heredity 93: 287-290.

HARJU, A. and MuONA, O. (1989): Background pollination in Pinus sylvestris L. seed orchards. Scand. J. For. Res. 4: 513-520.

JAMIESON, A. (1994): The effectiveness of using co-dominant polymorphic allelic series for (1) checking pedigrees and (2) distinguishing full-sib pair members. Animal Genetics 25: (Suppl 1) 37-44.

Jones, A. G. and ARdRen, W. R. (2003): Methods of parentage analysis in natural populations. Molecular Ecology 12: $2511-2523$.

Marshall, T. C., Slate, J., Kruuk, L. E. B. and Pemberton, J. M. (1988): Statistical confidence for likelihood-based paternity inference in natural populations. Molecular Ecology 7: 639-655.

Moran, G. F. and BeLL, J. C. (1987): The origin and genetic diversity of Pinus radiata in Australia. Theoretical and Applied Genetics 73: 616-622.

Moran, G. F., Bell, J. C. and Eldridge, K. G. (1988): The genetic structure and the conservation of the five natural populations of Pinus radiata. Canadian Journal of Forest Research 18: 506-14.

Nielsen, R., Mattila, D. K., Clapham, P. J. and Palsbøll, P. J. (2001): Statistical approaches to paternity analysis in natural populations and application to the north Atlantic humpback whale. Genetics 157: 1673-1682.

PaetKaU, D. and Strobeck, C. (1994): Microsatellite analysis of genetic variation in black bear populations. Molecular Ecology 3: 489-495.

RoEDER, K., Devlin, B. and Lindsay, B. G. (1989): Application of maximum likelihood methods to population genetic data for the estimation of individual fertilities. Biometrics 45: $363-379$.

Slate, J., Marshall, T. and Pemberton, J. (2000): A retrospective assessment of the accuracy of the paternity inference program CERVUS. Molecular Ecology 9: 801-808.

TABERLET, P. and LUIKART, G. (1999): Non-invasive genetic sampling and individual identification. Biol. J. Linnean Society 68: $41-55$.

WheELER, N. C. and $\mathrm{JECH}_{2}$ K. S. (1992): The use of electrophoretic markers in seed orchard research. New Forests 6: $311-328$

Worthington Wilmer, J., Allen, P. J., Pomeroy, P. P., Twiss, S. D. and Amos, W. (1999): Where have all the fathers gone? An extensive microsatellite analysis of paternity in the grey seal (Haichoerus grypus). Molecular Ecology 8: 1417-1429. 